\title{
DESENVOLVIMENTO DE FILMES ATIVOS BIODEGRADÁVEIS:FILMES DE AMIDO INCORPORADOS COM NANOPARTÍCULAS DE AMIDO E ÓLEO ESSENCIAL DE ORÉGANO
}

Karina Lizzeth Pedraza Galván1; Lucas Guimarães Cardoso2; Janaina de Carvalho Alves $^{2 ;}$ Madian Johel Galo Salgado2; Fernanda Antonia de Souza Oliveira2; Renata Quartieri Nascimento ${ }^{3}$; Jania Betania Alves Da Silva4; Janice Izabel Druzian³

\footnotetext{
${ }^{1}$ Universidade Federal da Bahia (UFBA), Faculdade da Farmácia / Salvador, BA, Rua Barão de Geremoabo, s/n, Campus de Ondina, 40170-210, Brasil. E-mail: pedrazagalvankarina@gmail.com

2Universidade Federal da Bahia (UFBA), Faculdade da Farmácia / Salvador, BA, Rua Barão de Geremoabo, s/n, Campus de Ondina, 40170-210, Brasil.

${ }^{3}$ RENORBIO/ UFBA. Universidade Federal da Bahia (UFBA) /Salvador - BA, Av. Reitor Miguel Calmon, s/n, Campus Canela, 40231-300, Brasil.

${ }^{4}$ Universidade Federal do Recôncavo Baiano (UFRB) / Salvador - BA, Rua Rui Barbosa, 710, Centro, Cruz das Almas - BA, 44.380-000, Brasil.
}

Resumo: O presente estudo teve como objetivo desenvolver filmes biodegradáveis de amido com nanopartículas de amido incorporados com o óleo essencial de orégano - OEO (Origanumvulgare), para aplicação como embalagem ativa na conservação de alimentos. Produção de filmes foi realizada utilizando o método de casting. Foram estudadas três concentrações do óleo essencial de orégano $(0,0 ; 5,0$ e $10 \%$ ). As propriedades físicas e mecânicas dos filmes produzidos também foram avaliadas. Para análise da eficiência antimicrobiana, foram utilizadas as metodologias da CLSI e APHA. A incorporação do óleo essencial de orégano influenciou no desempenho dos filmes. Os filmes com 5,0\% e $10 \%$ de OEO apresentaram eficiência antimicrobiana, quando comparado ao controle.

Palavras-Chave:Embalagens; Nanopartículas; Antimicrobiano; Óleo essencial.

\section{DEVELOPMENT OF BIODEGRADABLE ACTIVE MOVIES: STARCH MOVIES INCORPORATED WITH STARCH NOSE AND ORGAN ESSENTIAL OIL}

\begin{abstract}
The
presentstudyaimedtodevelopbiodegradablestarchfilmswithstarchnanoparticlesincorpo ratedwithoreganoessentialoil -OEO (Origanumvulgare), for application as activepackaging in food preservation. Filmproductionwasperformedusingthe casting method. Threeconcentrationsoforeganoessentialoil (0.0, 5.0 and $10 \%)$ werestudied. The physicalandmechanicalpropertiesofthefilmsproducedwerealsoevaluated. For analysisofantimicrobialefficiency, themethodologiesof CLSI and APHA wereused. The incorporationoforeganoessentialoilinfluencedthe performance ofthefilms. The filmswith $\quad 5.0 \%$ and $\quad 10 \% \quad$ OEO showedantimicrobialefficiencywhencomparedtothecontrol.
\end{abstract}

Keywords: Packaging; Nanoparticles; Antimicrobial; Essential oil. 


\section{INTRODUÇÃO}

Nos últimos anos, a utilização de embalagens biodegradáveis tem um aumento de $5 \%$ cada ano [1], sendo o amido, alginato, éteres de celulose, quitosano, carragenina ou pectinas alguns dos biopolímeros mais utilizadas na produção de embalagens [2]. O amido tem-se destacado por ser abundante e o de menor custo, além de apresentar possibilidades de modificação química, física ou genética, originando filmes resistentes e biodegradáveis [3].

No entanto, muitos desses polímeros biodegradáveis possuem problemas relacionados ao desempenho, como baixa resistência mecânica e térmica, apresentando fragilidade e baixa temperatura de deformação, além da fraca barreira a umidade, limitando o uso das embalagens biodegradáveis por parte das indústrias [4]. A nanotecnologia vem por meio da utilização de nanopartículas melhorar as características mecânicas e térmicas destes filmes, como alternativa na solução dos problemas de desempenho dos filmes de amido. Devido, ao seu tamanho nano, podem apresentar novas e aprimoradas propriedades físicas, químicas e biológicas [5], e melhores funcionalidades quando comparados com o material em maior tamanho [6].

Além da melhoria das propriedades citadas, busca-se também um avanço na segurança, qualidade e da vida de prateleira de alimentos prontos para o consumo. De acordo com o Ministério da Saúde [7] as bactérias Salmonella spp., Escherichia coli, e Staphylococcus aureus, são uma das principais causadoras de doenças transmitidas por alimentos (DTA). Com isso, embalagens incorporadas com antimicrobianos visam ter uma proteção maior e aumentar a vida de prateleira dos alimentos. Os óleos essenciais de plantas são um exemplo de potenciais antimicrobianos naturais bastante estudados para aplicação em alimentos [8]. $O$ alimento como o queijo comumente utilizado na dieta da população, compondo, geralmente, a alimentação de todas as classes sociais [9]. Caracteriza-se como um produto altamente perecível, contém altos teores de proteína e lipídeos, sofrendo muitas reações de deterioração, alguns deles com alta umidade e, possui nutrientes importantes para o desenvolvimento microbiano [10]. Ter uma embalagem apropriada para esse tipo de alimento é de extrema importância para manter a qualidade durante seu armazenamento. O objetivo do presente estudo foi desenvolver filmes biodegradáveis de amido com nanopartículas de amido e óleo essencial de orégano (Origanumvulgare), para aplicação como embalagem ativa na conservação, visando o controle da população microbiana em queijo muçarela.

\section{METODOLOGIA}

As análises foram realizadas no laboratório de Pescado e cromatografia aplicada (LAPESCA). Foram utilizados, amido de milho (DURYEA®), nanopartículas de amido, glicerol (SYNTH®) como plastificante e óleo essencial de orégano (FERQUIMA®). As nanopartículas de amido milho foram preparadas pelo método de ultrassom, em um sonicador modelo Q55 (Estados Unidos), segundo metodologia de 
Pereira et al., [11]. A suspensão coloidal foi congelada e submetida à secagem por congelamento (liofilização), obtendo nanopartículas com diâmetros de aproximadamente $400 \mathrm{~nm}$.

\subsection{Preparação dos filmes}

Os filmes foram preparados segundo a técnica casting. Desenvolvidos com concentração de 4,0 g de amido, 0,25 g de nanopartículas de amido e 2,1 g de glicerol/100 g de solução filmogênica. Os filmes foram preparados com três diferentes concentrações do óleo essencial de orégano $(0,0 ; 5,0 ;$ e $10,0 \%)$, respectivamente, em relação à solução filmogênica total.

\subsection{Propriedades Mecânicas}

Os filmes foram caracterizados quanto à espessura mediante leitura com micrômetro manual (MitutoyoCorp.) e submetidos a testes de tração para avaliação tensão e deformação na carga máxima de acordo com a norma ASTM D882- 09 [12], utilizando a máquina Universal de Testes Mecânicos (INSTRON Corporation, Norwood, MA, USA). Foram testados dez corpos de prova de cada formulação com dimensões de $10 \mathrm{~cm}$ de comprimento e $2,5 \mathrm{~cm}$ de largura. A máquina foi operada com carga de $1 \mathrm{kN}$ a uma velocidade de tração de $5 \mathrm{~mm} / \mathrm{min}$.

\subsection{Análise Antimicrobiana In Vitro.}

A avaliação da atividade antimicrobiana dos filmes com óleo essencial foi realizada utilizando a técnica de difusão em ágar com discos dos filmes preparados. Foram utilizadas culturas de Escherichia coli, Staphylococcus aureus e Salmonella spp. De acordo com metodologia do Manual ClinicalandLaboratory Standards Institute (CLSI) [13], inóculos de cada microrganismo foram preparados por meio da suspensão direta, em solução salina esterilizada, de colônias isoladas, selecionadas de placas de Ágar tripticase de soja (TSA), e incubados a $35^{\circ} \mathrm{C}$ por $18-24 \mathrm{~h}$.

\subsection{Análise Antimicrobiana In Vivo.}

Os filmes foram cortados em tamanhos definidos, suficiente para cobrir as superfícies das fatias de queijo muçarela. $O$ alimento acondicionado nos filmes antimicrobianos foi armazenado a $8 \pm 2 \stackrel{\circ}{\circ}$. As análises microbiológicas do queijo foram realizadas, de acordo com a metodologia descrita pela American Public Health Association (APHA) [14] nos tempos 0, 7, 14, 21 dias

\section{RESULTADOS E DISCUSSÃO}

O aspecto visual do filme de $0 \%$ (Figura 1-A) composto de amido, 0,25 $\mathrm{g}$ de nanopartículas de amido e $0 \mathrm{~g}$ de OEO (filme controle), foi o que apresentou melhor homogeneidade, transparência, brilho, flexibilidade e sem 
dificuldade para retirada da placa de secagem. O filme com 5\% (Figura 1-B) teve homogeneidade um pouco menor quando comparado com o filme controle, além disso, apresentou boa flexibilidade, transparência, brilho e pouca dificuldade para retirada na placa de secagem. Já o filme com $10 \%$ (Figura 1-C) apresentou menor homogeneidade quando comparado aos demais filmes, apresentou mudança na coloração, devido a uma maior concentração do OEO, e com maior dificuldade para retirada das placas de secagem.

Figura 1. Filmes de amido incorporados de nanopartículas de amido, glicerol e $0 \%$ (A), $5 \%$ (B) e 10\% (C) de óleo essencial de orégano como agente antimicrobiano.
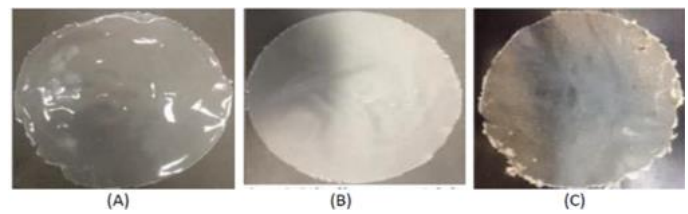

\subsection{Propriedades mecânicas}

Os resultados dos testes mecânicos expresso na figura 2 demonstram que o aumento da concentração OEO diminuiu à tensão máxima, deformação e módulo de elasticidade dos filmes. Como observado nos gráficos da figura 2 ( $A, B, C)$. As formulações $5 \%$ e $10 \%$ apresentaram resultados inferiores quando comparados ao controle (F0). Estudos realizados com nanopartículas de amido feito por Li et al. [15], mostraram que filmes com $5,0 \%$ de nanopartículas apresentaram tensão máxima de 9,96 MPa, com aumento de 72,9\% em relação ao filme controle sem nanopartículas. E a deformação na ruptura diminuiu $12,58 \%$, mostrando que a adição de OEO contribuiu para redução desses parâmetros.

Figura 2: Propriedades mecânicas - Tensão (A), Deformação (C) Módulo elásticidade dos filmes de amido incorporados com nanopartículas de amido e com $0 \%$ (F0), $5 \%$ (F5) e 10\% (F10) de óleo essencial de orégano.
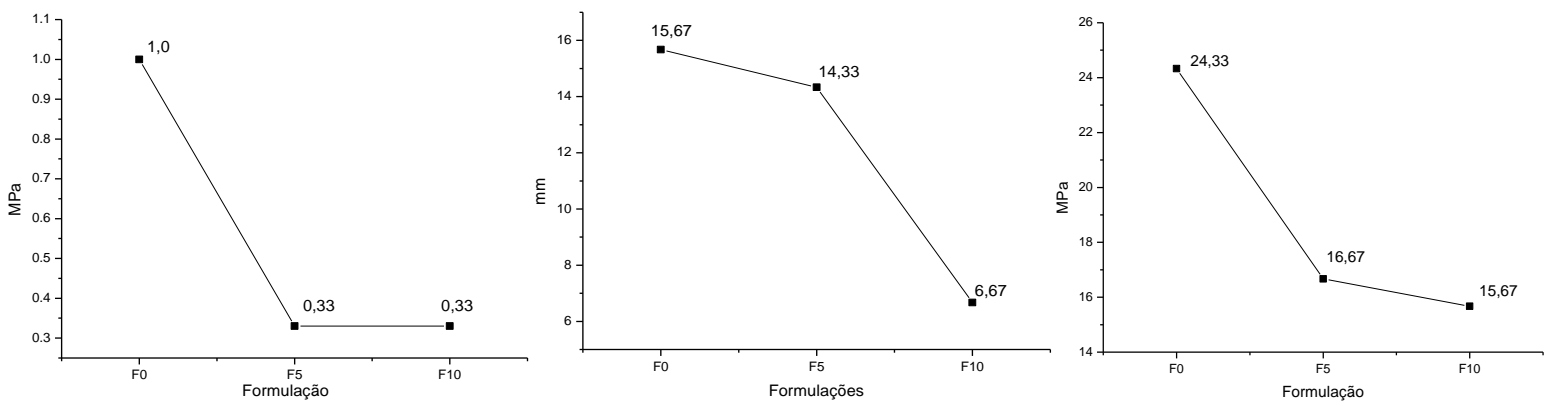

Daí et al. [16], verificaram que a adição de 10\% de nanopartículas de amido aumentou a tensão máxima a 2,87 MPa, a justificativa para a melhoria das propriedades mecânicas do filme foi devido à alta área de superfície específica provida pelas nanopartículas, causando maior resistência na interface da matriz de 
preenchimento nas interações dos filmes. A concentração de nanopartículas utilizada tem forte influência nas propriedades dos filmes [17].

Resultados semelhantes ao presente estudo foram apresentados por Martucci et.al. [18], onde foram avaliadas as propriedades mecânicas de filmes de gelatina biogênica com óleo essencial de orégano como antimicrobiano. Segundo os autores, a adição do óleo afetou significativamente a resistência à tração e a capacidade de alongamento dos filmes obtidos. A incorporação do óleo possivelmente resultou na diminuição da interação entre monômeros da gelatina, impedindo as interações de cadeia-cadeia de polímero, e consequentemente, levou ao comprometimento das propriedades mecânicas. Do mesmo modo, nos filmes de amido produzidos, a incorporação do OEO, possivelmente, resultou na diminuição da interação entre os monômeros de glicose que compõem o amido, resultando na diminuição da tensão.

\subsection{Atividade Antimicrobiana In Vitro}

A partir dos resultados obtidos in vitro, observou-se que com o aumento da concentração do óleo essencial de orégano, maior foi à sensibilidade (Tabela 1). 0 $\mathrm{S}$. aureus foi o microrganismo que apresentou maior sensibilidade ao filme, com halos $26 \mathrm{~mm}$ e $36 \mathrm{~mm}$ nas concentrações de 5\% e $10 \%$ do óleo essencial de orégano, respectivamente, como mostra a tabela 1. Em estudo realizado por Botre et al. [19] também foi constatado atividade antimicrobiana contra $S$. aureus em filmes com $50 \%$ óleo essencial de orégano. Os autores constataram que o filme incorporado com $25 \%$ de óleo essencial de orégano formou um halo de inibição maior, demonstrando que quanto maior a concentração de óleo essencial, maior atividade antimicrobiana.

Tabela 1. Medidas dos halos de inibição do crescimento microbiano de Escherichia coli, Staphylococcus aureus e Salmonella spp, sob diferentes porcentagens de óleo essencial de orégano em filmes de amido, nanopatículas de amido.

\begin{tabular}{l|c|c|c}
\hline Amostras & $\begin{array}{c}\text { Escherichia coli } \\
(\mathbf{m m})\end{array}$ & $\begin{array}{c}\text { Staphylococcus aureus } \\
(\mathbf{m m})\end{array}$ & $\begin{array}{c}\text { Salmonellaspp } \\
(\mathbf{m m})\end{array}$ \\
\hline Filme 0\% & 0 & 0 & 0 \\
\hline Filme 5\% & 21 & 26 & 21 \\
\hline Filme 10\% & 28 & 36 & 24 \\
\hline
\end{tabular}

*Média das duplicatas

Segundo Medeiros [20] o filme de acetato de celulose incorporado com 50\% óleo essencial de orégano apresentou atividade antimicrobiana sobre S. aureus. obtendo halo de inibição médio de $20 \mathrm{~mm}$. Mostrando também atividade antimicrobiana contra Staphylococcus aureus. Javidi et al. [21], analisaram a efetividade microbiológica de películas de PLA (poli ácido lático), obtidas pelo método de casting, incorporadas com OEO, frente a $S$. aureus, Listeria. monocytogenes, E. coli e S. enteritidis. Obtiveram uma melhor ação antimicrobiana frente a bactérias Gram-negativas. Diferente do presente estudo, onde os filmes antimicrobianos apresentaram melhor efetividade frente a bactéria Gram-positiva (S. aureus), podendo estar relacionado a forma de obtenção dos filmes e a interação existente entre o polímero e o óleo essencial. 
De acordo Silva [22] a ação antibacteriana dos óleos essenciais varia significativamente em função da bactéria, sendo a sensibilidade maior para bactéria Gram positiva em relação à Gram negativa. Uma explicação possível para as diferenças observadas quanto à sensibilidade bacteriana, pode ser a existência de diferenças na estrutura da parede bacteriana, como por exemplo, a presença de lipopolissacarídeo nas bactérias Gram negativas e ausência nas Gram positivas, que permite ou não a entrada de substâncias na célula bacteriana, interferindo assim na ação sobre o microrganismo.

\subsection{Atividade antimicrobiana na matriz alimentícia}

Foi realizada a análise microbiológica do queijo fatiado tipo muçarela no tempo 0 (tabela 2), que demostrou estar de acordo com os limites microbiológicos estabelecidos pela RDC-12, a qual estabelece limite de S. aureus de $10^{3} \mathrm{UFC} / \mathrm{g}$, Coliformes termotolerantes de $5 \times 10^{2} \mathrm{UFC} / \mathrm{g}$ e ausência de Salmonella spp. $25 \mathrm{~g} \mathrm{em}$ queijos tipo muçarela [24].

Tabela 2. Análise microbiológica do queijo no tempo de 0 dias

\begin{tabular}{c|c}
\hline & \\
\hline Coliformes Termotolerantes & Ausente \\
\hline Coliformes Totais & $2,0 \times 10^{-1}$ \\
\hline S.aureus & $1,7 \times 10^{-2}$ \\
\hline Salmonella spp & Ausente \\
\hline Mesófilos & $2,0 \times 10^{-2}$ \\
\hline
\end{tabular}

Os filmes contendo $10 \mathrm{~g}$ de OEO tiveram variações diferentes na sua efetividade antimicrobiana quando comparado aos filmes contendo $5 \mathrm{~g}$ de OEO nos testes in vivo e in vitro. Entretanto, os filmes contendo $5 \mathrm{~g}$ e $10 \mathrm{~g}$ de OEO, conseguiram ser efetivos até o $14^{\circ}$ dia. $O$ que fez estender a vida útil do queijo em 12 dias, de acordo com a legislação vigente RDC de $n^{\circ}$ 12. Melo [25] não conseguiu prolongar a vida de prateleira da carne de frango resfriada através do armazenamento em filme de base celulósica adicionado de $20 \%$ de óleo essencial de alecrim, no período de nove dias de estocagem, apesar de a inibição ter sido comprovada nos testes in vitro. Com isso acredita-se que o tipo de matriz alimentar é um fator importante que pode interferir nesse processo, pois podem ocorrer interações entre os compostos antimicrobianos e os componentes dos alimentos, como proteínas e gorduras, que podem influenciar na eficácia desses compostos.

De acordo com Cardoso et al. [26], filmes de PBAT incorporados com diferentes concentrações de OEO, nos quais foram embalados filetes de peixe, também se mostraram eficientes na diminuição das contagens de coliformes totais, Staphylococcus aureus e microrganismos psicrotróficos. O que ocasionou aumento de vida útil dos filetes por até 10 dias. O que nos mostra que o OEO tem uma ação antimicrobiana in vivo efetiva. Botre et al. [19] que analisaram filmes de resina celulósica adicionada de 25 e $50 \%$ de OEO embalados em pizzas prontas, não obtiveram inibição do crescimento de psicrotróficos. No entanto, o crescimento de fungos filamentosos e leveduras apresentaram pequena inibição após 15 dias de estocagem a $7^{\circ} \mathrm{C}$, quando submetidos ao tratamento com $50 \%$ de orégano. Em 
contrapartida um estudo feito por Soares et al. [27], revelou uma redução de 0,5 e 1,0 ciclo log no crescimento de Listeriainnocua nos queijos tipo frescal acondicionados em presença dos filmes contendo OEO, em relação ao controle, ao final do período de estocagem (12ํำ dia), confirmando o potencial de utilização do OEO como agente antimicrobiano em embalagens ativas.

\section{CONCLUSÃO}

Conclui-se que a partir dos resultados apresentados, a incorporação do óleo essencial de orégano interfere no desempenho dos filmes de amido e nanopartículas de amido, reduzindo a resistência mecânica. Os filmes de 5\% de OEO e $10 \%$ de OEO apresentaram eficiência antimicrobiana nas análises in vitro e in vivo, demonstrando assim, seu potencial como ferramenta para a manutenção da qualidade do alimento. O que tornam esses filmes uma alternativa para redução no uso de plásticos convencionais no acondicionamento de alguns alimentos. Entretanto existe a necessidade de estudos adicionais, que avaliem a ação desses filmes em outras matrizes alimentares.

\section{REFERÊNCIAS}

1. DA ROCHA, M. et al. BiodegradableFilms: AnAlternative Food Packaging. In: Food PackagingandPreservation. Academic Press, p. 307-342. 2018.

2. VIEIRA, M. G. A. et al. Natural-basedplasticizersandbiopolymerfilms: A review. European Polymer Journal, v. 47, n. 3, p. 254-263, 2011.

3. MALI, S. et al. Watersorptionandmechanicalpropertiesof cassava starchfilmsandtheirrelationtoplasticizingeffect. Carbohydratepolymers, v. 60, n. 3, p. 283289, 2005.

4. ASSIS, L. M. de et al. Characteristicsofnanoparticlesandtheirpotentialapplications in foods. BrazilianJournalof Food Technology, v. 15, n. 2, p. 99-109, 2012.

5. MIYAZAKI, K., ISLAM, N. Nanotechnology systems ofinnovationAnanalysisofindustryand academia researchactivities. Technovation, v. 27 p. 661-675. 2007.

6. BOCCUNI, F., RONDINONE, B., PETYX, C., \& IAVICOLI, S. Potentialoccupationalexposuretomanufacturednanoparticles in Italy. Journal of CleanerProduction, v. 16, p. 949-956, 2008.

7. BRASIL. Ministério da Saúde. Doenças Transmitidas por Alimentos. 2018 http://portalarquivos2.saude.gov.br/images/pdf/2018/janeiro/17/ApresentacaoSurtosDTA-2018.pdf. Acesso em 15. Mar. 2018.

8. CHEN, W.P; WANG, B.J.; WENG, Physiochemicalandantimicrobialpropertiesofediblealoe/gelatincompositefilms. InternationalJournalof Food Science and Technology, Oxford, v.45, p.1050-1055, 2010.

9. SILVA, J. F. Q., FILIZOLA, L. R. S., MAIA, M. M. D. \& SENA, M. J. Utilização de coliformes termotolerantes como indicadores higiênicosanitários de queijo Prato comercializado em supermercados e feiras livres de Recife-PE. Revista de Medicina Veterinária, v1, p.21-25, 2011.

10. SANGALETTI, N., et al. Estudo da vida útil de queijo Minas. Ciência e Tecnologia de Alimentos, v. 29, n. 2, p. 262-269, 2009.

11. BEL HAAJ.S.; MAGNIN, A.; PETRIER, C.; BOUFI, S. Starchnanoparticlesformation via high powerultrasonication. CarbohydratePolymers, v.92, p.1625-1632, 2013. 
12. ASTM D882-09, 2009. Standard testmethod for tensilepropertiesofthinplasticsheeting. 468 Annual Book of ASTM Standards. Amer. Soc. for TestingandMaterials, Philadelphia, PA.

13. CLSI. Perfomance Standards for AntimicrobialSusceptibilityTesting; TwentyThirdInfomationalSupplement. CLSI document M100-S23. ClinicalandLaboratory Standards Intitute, Wayne, PA, USA. 2013.

14. AMERICAN PUBLIC HEALTH ASSOCIATION (APHA). Compendiumofmethods for themicrobiologicalexaminationoffoods. $4^{\circ}$ ed. Washington: APHA. 676 p. 2001.

15. LI, X.; QIU, C.; JI, N.; SUN, C.; XIONG, L., SUN, Q. Mechanical, barrierandmorphologicalpropertiesofstarchnanocrystals-reinforcedpeastarchfilms. CarbohydratePolymers v.121, p.155-162, 2015.

16. DAI, L., QIU, C., XIONG, L., \& SUN, Q. Characterisationofcornstarchbasedfilmsreinforcedwith taro starchnanoparticles. Food Chemistry, 174, 82-88, 2015.

17. LE CORRE, D., BRAS, J., \& DUFRESNE, A. Starchnanoparticles: A review. Biomacromolecules, v.11, p.1139-1153, 2010.

18. MARTUCCI, J.F., GENDE, L.B., NEIRA, L.M., RUSECKAITEA, R.A. Oreganoandlavenderessentialoils antioxidantandantimicrobialadditivesofbiogenicgelatinfilms. Industrial CropsandProducts, v. 71, p. 205-213, 2015.

19. BOTRE, D. A., SOARES, N. F. F., ESPITIA, P. J. P., SOUSA, S. \& RENHE, I. R. T. Avaliação de filme incorporado com óleo essencial de orégano para conservação de pizza pronta. Revista Ceres, v. 57 (3), p. 283-291, 2010.

20. MEDEIROS, E.A.A et al. Atividade antimicrobiana de filme de acetado de celulose incorporado com olé essencial de óregano (Origanumvulgare L.) em queijo minas frescal. Xxv CBCTA - Ufrgs, Gramado, p.1-6, out. 2016.

21. JAVIDI, Z., HOSSEINI, R.F., REZAEI, Developmentofflexiblebactericidalfilmsbasedonpoly (lacticacid) andessentialoiland its effectivenesstoreduce microbial growthofrefrigeratedrainbowtrout. LWT - Food Science technology. v. 72, p. 251-260, 2016.

22. SILVA, M.T.N. et al. Atividade antibacteriana de óleos essenciais de plantas frente a linhagens de Staphylococcus aureus e Escherichia coli isoladas de casos clínicos humanos. Rev. Bras. Plantas Me. v. 11, n. 3, p. 257-262, 2009.

23. FERNANDEZ-SAIZ, P., OCIO, M.J., LAGARON, J.M. Antibacterialchitosanbasedblendswithethylenevinylalcoholcopolymer.

CarbohydratePolymers, v. 80, n. 3, p. 874-884, 2010.

24. BRASIL. Agência Nacional de Vigilância Sanitária. Resolução - RDC no. 12, de 2 de janeirode 2001. Regulamento técnico sobre os padrões microbiológicos para alimentos. http://www.anvisa.org.br. Acesso em 15. Mar. 2018

25. MELO, A. A. M. Efeito de filme ativo incorporado com óleo essencial de alecrim (Rosmarinusofficinalis L.) na conservação de carne de frango resfriada. 2010. Dissertação (Mestrado em Ciência e Tecnologia de Alimentos) - Escola de Agronomia e Engenharia de Alimentos, Universidade Federal de Góias, Goiânia-GO

26. CARDOSO, L. G.; SANTOS, J. C. P.; CAMILLOTO, G. P.; MIRANDA, A. L.; DRUZIAN, J. I.; GUIMARÃES, A. G. Developmentofactivefilmspoly (butyleneadipatecoterephthalate) - PBAT incorporatedwithoreganoessentialoilandapplication in fishfilletpreservation. Industrial Crops\&Products, v. 108, p. 388-397, 2017.

27. SOARES, N. F. F., Silva, P. S. \& Silva, W. A. Desenvolvimento e avaliação de filme ativo incorporado com óleo essencial de orégano (Origanumvulgare L.) no crescimento de Listeriainnocua em queijo Minas frescal. Revista do Instituto de Laticínios Cândido Tostes, v.365, n. 63, p. 36-40. 2008. 